\title{
THERMODYNAMICS, HANDMAIDEN TO SCIENCE AND TECHNOLOGY*
}

\author{
E. F. Westrum, Jr. \\ DEPARTMENT OF CHEMISTRY, THE UNIVERSITY OF MICHIGAN, \\ ANN ARBOR, MICHIGAN 48109 USA
}

(Received October 1, 1982)

\begin{abstract}
Generally, the only items of reference data with real economic impact are-except in a few instances-the basic values from which the standard enthalpy increment of reactions and the Gibbs energy of formation of the substances involved in the reaction. The energetic requirements of chemical processing mandate exact values here as well as for rather precise Gibbs energies needed for evaluation of equilibrium constants. Even here the contribution may lie less in the intrinsic value of that accuracy than in the implicit reliability and ready availability of the tables. CODATA's endeavors and scientific task groups dealing with fundamental constants, key values for thermodynamics, internationalization and systematization of thermodynamic tables to assist chemical industry are noted.
\end{abstract}

Without a steady flow of quantitative data the progress of science would be impeded, and without numerical data on working fluids and materials, industry would be condemned to a costly step-by-step development of nearly full-scale equipment. But. more specifically how important are thermodynamic data in this respect and how important are highly accurate thermodynamic data? How does the emergence of fast computers and reliance on data banks change the modus operandi of design development, the analysis of masses of experimental data, and the formulation/validation of internally consistent algorithms.

Historically approached, the translation of scientific understanding into useful technology has shown the inherent virtue-and the utility-of "gold-plated data". In current times the now famous CODAN report deals with the cost effectiveness and economic value of data and the truism "unreliable data are worse than no data at all". But will the need for the flow of data soon cease? Has thermodynamics been outmoded by recent developments - or do we need an enhanced endeavor requiring exchange and cooperation on an international scale?

\footnotetext{
* Presented at the Second Czechoslovakian Conference on Calorimetry. The author acknowledges the continuing support of the Structural Chemistry and Chemical Thermodynamics Program of the Chemistry Section of the National Science Foundation under Grant CHE-7710049 in his research endeavors.
} 


\section{Credo}

Most chemical thermodynamicists will be acquainted with the excellent new chemical thermodynamic monograph by Professor Max McGlashan [1]. It contains many controversial statements - some with which I disagree heartily and at least one to which 1 thoroughly subscribe-it is simply: "Thermodynamics is an experimental science, not a branch of metaphysics."

Without quantitative data, thermodynamics-or for that matter-physics and chemistry, would soon become an empty shell of unverified speculation. Progress would be severely impeded and would, eventually, stop. Without numerical data describing the properties of metallurgical materials, of working fluids, and of structural materials, technology and applied science would be condemned to a laborious, empirical, step-by-step construction of nearly full-scale equipment. This would be prohibitively costly and would bring economic progress to a standstill.

To chemical thermodynamicists the above truths will probably seem self-evident. However, they are not necessarily self-evident to the external world, to the scientific establishment, to the industrial engineers and managers, or to national policy makers. They are regarded neither as a desperate negation nor as a triumphant affirmation.

Thermochemists and thermophysicists are generally committed to the idea that a steady flow of data on the thermodynamic properties of a wide variety of materials is needed for the good health of science and for continuing improvement of technology. This is especially so at this juncture when the civilized world has-of necessity-become engaged in a major shift to new energy sources with emphasis on high efficiency. (In my own research motivated by the study of transitions-crises in Gibbs energies - we have always taken the attitude that a worthwhile by-product of our study of the energy spectrum of solid and fluid matter through heat-capacity measurements was the thermodynamic functions themselves.)

Thermodynamicists will generally adopt the position that the need of this flow of data will never cease. In fact, the presence of most of the participants of this meeting is a tribute to the fact that we have individually undertaken the self-appointed task of personally contributing to this flow of data. Clearly the total task requires exchange and cooperation on a national and an international scale. The task is not one for an ivory-tower philosopher who creates in isolation, but is one that requires cooperation between the academic researcher, the industrial practitioner, the scientific worker employed by the government and the administrative decision maker in the public as well as the private sector. 


\section{A bit of history}

\section{Excellence in science}

Three or four decades ago it was considered self-evident that meticulous and precise determination of thermodynamic properties was intrinsically virtuous-and, therefore useful-and the only questions one posed to himself were what one could do better than anyone else. Excellence was respected.

More recently life has become much more complex and we all realize that the needs of science and industry can never be met completely by direct measurement only. The number of pure substances and mixtures, the number and complexity of the properties needed over enormous ranges of pressure and temperature are so vast that the joint efforts of the scientific establishment of the whole human race have become inadequate for such a monumental task. This seemingly unmanageable situation still confronts us today, but a discussion of this aspect will be postponed for the moment.

\section{The dawn of cost-effectiveness}

As time progressed more and more resources were poured into data gathering; international cooperation became international competition. In such a situation it is only a matter of time until someone begins to question the purpose of it all and the concept of cost-effectiveness is born. Scientists were challenged by industry and government to articulate their intuitive conviction of the real importance of our contributions and quantification in "dollars and cents", in "pounds and pence", in "francs and centimes". It was an international challenge, but, since I know best-from painful experience - the situation in my own country, I will describe it, confident that parallels exist elsewhere.

\section{Quantification}

The Office of Standard Reference Data of our National Bureau of Standards has struggled with the problem since its inception as is shown by 16 years of annual reports and David Lide's recent article in Science [2]. I was called to testify to this before the Congress of the United States and its budgetary committee. Our National Academy of Sciences prepared the now famous CODAN report [3] under the chairmanship of Walter Stockmayer. This has been - in my judgement - the most convincing of all reports although it seldom refers to thermodynamics.

But there will be more reports as we thermodynamicists-for example-must continue to explain to funding agencies why our work is necessary. Its absence would be disastrous; but $100 \%$ quantification is just not feasible.

Several of my colleagues have found it possible to teach thermodynamics by the case-study approach. Several examples will be used to illustrate the historical experience in several fields of science and to see in sharp relief by what mysterious ways progress is made-despite the unquantifiable consequences of our research endeavors. 
An example from World War II. In the CODAN report [3] already mentioned, Stockmayer reminds us that the fate of the "atomic bomb" Manhattan Project turned at one point on the development of graphite-moderated fission reactors, the feasibility of 'which, in turn, depended on an accurate knowledge of the capture cross-section of neutrons in carbon. Fermi's 1940 measurement clinched the matter, and the United States launched the Project. By contrast, the German authorities stopped their reactor program owing to an erroneous evaluation of an erroneous measurement of the same quantity.

Now, imagine that you are asked to judge the cost-effectiveness of Fermi's measurement, or of the German's attempt either before the event, after it, or even now with hind-sight. Reasonable judgement tells us today - and told our predecessors then - that these measurements were crucial; but no one can even now quantify their value.

Mendeleev's periodic table. The existence of numerical data describing the atomic and molecular structure of the elements enabled Mendeleev - and Lothar Meyer-to predicate the periodic table.

Lord Rayleigh's Nobel Prize. Let me cite just one other well-known example, that involving the density of nitrogen gas. He had done it once, and in his own words [4]: "... but then I reflected that it is a/ways advisable to employ more than one method ..."

To make a long story short, he found that the density of nitrogen from air bubbled through ammonia and from air whose oxygen was absorbed by red hot copper metal differed by $0.1 \%$.

Now, who needs the density of nitrogen to one part in 1000 ? The derisive name for this level of accuracy is a quest for "gold-plated numbers".

But fortunately Lord Rayleigh was undeterred and found ways of magnifying the difference between the density of atmospheric and of chemical nitrogen to about $0.4 \%$. The experiments led to the isolation of argon, to the Nobel Prize, and to the creation of an entire industry based on the properties of argon and the even less abundant constituents of the atmosphere.

It would be unreasonable to advocate making every measurement to the limit of accuracy. Life is too short for that, our resources too small. But the cultivation of accuracy is not to be sneered at.

\section{Technology, thermodynamics and data bases}

The translation of scientific understanding into useful technology cannot occur without numerical data which describe, for example, the thermodynamic properties of working fluids. In the not too distant past, designers were satisfied to work with handbooks which gave them discrete numbers of limited reliability, or with thermodynamic charts. As time progressed, the influence of science on design grew and the 
larger companies began to develop loose-leaf books of more or less proprietary data for the use of their engineering staffs, particularly in the chemical industry. But this proved to be a hopeless race between ever-widening needs and the limitations of handbooks and graphs.

in our contemporary world, designers typically examine a number of alternative concepts before making a decision. The press for efficiency puts new demands for optimization. The increased reliance on scientific principles makes it possible to omit intermediate states in industrial development and prototype construction. The organization and maintenance of vast data bases in on-line computers has now become indispensable for practically every stage of design. Such data banks are also indispensable for regulatory purposes both with respect to safety and environmental protection. This explosive development of computerized data handling has revolutionized design practices. However, it is even more necessary to develop methods of critical estimation, validation, and correlation to enable the computer to produce reliably interpolated data at various stages of design, development, and testing. Thus, the direct usefulness of reliable thermodynamic data is clear.

Can we attach an economic value to such data? Paradoxically, the full value becomes evident only if we examine

- the consequence of the absence of data, or

- the consequence of the lack of confidence in data that happen to be available, or even more paradoxically.

- the consequence that "unreliable data can be worse than do data at all" [3].

In the face of unreliable data, the designer adopts a defensive strategy and overdesigns by incorporating larger than necessary safety factors to achieve success. While it is fairly easy to determine the sums lost on a plant that does not work, it is virtually impossible to estimate the economic loss in a plant that works well but is overdesigned. This explains the difficulty that many committees have encountered when they attempted to quantify the avoidable waste of design based on unreliable, inadequate, or erroneous data.

It is natural for you to ask at this state for concrete examples to illustrate my thesis. These are not easy to provide for the simple reason that failures are almost never advertised in print nor discussed at scientific, technological, or professional meetings, though perceptive designers are keenly aware of the problem.

\section{Are highly accurate property data on pure compounds useful to industry?}

In 1977 the National Research Council with the help of the Industrial Research Institute (IRI) surveyed the 243 member companies. Of those that responded, $71 \%$ indicated a need for thermodynamic data (second only to a $73 \%$ response to a need for electrical data) [5]. However, in general, highly reliable (literature) data on physical 
properties of pure compounds are important in but few areas of industrial technology. High precision properties of pure compounds are only moderately useful in process design because of the crudity of the mixing rules with which the pure-compound data are generally converted to the mixed-stream property data that are really needed. Even the extremely important relative volatility data for separation processes are only moderately sensitive to the precision of the pure-compound input data, since they are often dominated by non-ideality corrections. Moreover, given their great leverage on plant costs, the final design data are generally determined experimentally if there is even the slightest doubt regarding the calculated values upon literature-derived estimates.

Consequently, the value of high-accuracy property data often lies less in the intrinsic value of that accuracy than in the implicit reliability of a set of literature data, so that the engineer who refers to them can accept them without the expense of doubts, further checks, and/or further searches. The ready availability of such data in a well-known source has a substantial economic value if one remembers that process design engineers are known to spend more than half of their valuable time on the search for (reliable) property data. Many examples demonstrate the sensitivity of some important plant cost elements to uncertainty in property data. In the actual case, the uncertainties for individual plant components interact with each other and only their combined effect spells out the cost of an uncertainty in some crucial element. Hence, the cost effects of data uncertainties can be much larger-or much smaller-than anticipated; frequently they are smothered by other design uncertainties.

\section{Thermophysical and thermochemical data}

One important set of data falls outside this gloomy portrayal, the enthalpy and the Gibbs energy increment of chemical reactions, commonly derived from enthalpies of combustion, i.e., (thermochemistry), third-law, and spectroscopic data, (i.e., thermophysics). That is:

$$
\Delta G_{\mathrm{r \times n}}^{0}=\Delta H_{\mathrm{r \times n}}^{0}-T \Delta S_{\mathrm{rxn}}^{0}=\sum_{i}\left(\Delta H_{f}^{0}\right)_{i}-T \sum_{i} S_{i}^{0}=R T \ln K_{\mathrm{eq}} .
$$

(These equations, of course, relate calorimetric values to equilibrium properties and hence are the fundamental pillars of our thermodynamic science.) Few industrial organizations need these data frequently enough to maintain the very high experimental skill level required for useful data generation; hence, virtually everyone relies on published data. Since the needed reaction enthalpies are small, differences between large numbers, errors in excess of $0.1 \%$ in the enthalpies of combustion, are quite intolerable.

Many modern plants rely for their operability upon the clever combination of exothermic and endothermic reaction steps for capital and operating cost minimization. Here the accuracy and precision of the basic data can be spelled out in large financial amounts, but will rarely be told because of the proprietary nature of the information. The accuracy and precision of the Gibbs energy data required for 
meaningful estimates of equilibrium product distributions is an order of magnitude greater than is that for reaction enthalpies alone. The need for more precise data and for their critical evaluation is, therefore, quite overwhelming.

\section{In real life...}

It is many impression that in actuality there is less than $0.1 \%$ probability that reasonably reliable physical property data exist for all the substances under consideration in any given novel, chemical-synthesis process! Hence, the most important function of "standard reference" data is their extrapolatability to other compounds. The real reason for the needed high accuracy and precision is the dependence of the extrapolation to novel compounds-for example by the development of molecular structure increments. These generally small differences between large numbers are recombined and consequently cumulate all the errors found along the way, but more and more experimentalists need to select the substances they study with great care to enable appropriate correlation and estimation to new and novel compositions of matter.

\section{The economic benefits}

Two kinds of economic benefit are identifiably associated with high accuracy, mutually consistent thermodynamic data:

- reduction in the uncertainty of chemical reactor and/or design through the reduction in the uncertainty of heat balancing (which becomes the more significant the larger and the more highly integrated the plant).

- prediction of process feasibility on the basis of thermochemical equilibria.

Given the large number of exploratory investigations per successful development. the ability to guess correctly whether an idea has any promise at all is increasingly valuable as the chemical world becomes increasingly competitive. A missed opportunity because of an incorrectly predicted positive Gibbs energy increment can be even worse than the time wasted on "fighting" the second law in the opposite case. The past is probably not a good guide for measuring the economic significance of this point because of the increasingly sophisticated syntheses required in a world in which most of the easy things have been done already [6]!

Consequentiy, one must recognize that a substantial portion of the economic impact of the Standard Reference Data is simply due to their availability as "unquestionably reliable" information. A presumably measurable part of this potential benefit is the reduction in engineers' and chemists' search time. In order to maximize this benefit, the potential user must not only know that the information exists, he must also be able to gain rapid access to the data of interest. 


\section{New directions for thermodynamic measurements}

If we can concur on the principle that the fullest application of thermodynamics is prerequisite to the technological development of new processes, there is still the question of how to get a maximum yield from new measurements. Since there is no hope of measurement of all the systems which might be of interest for some development, it is important to devise models that enable prediction of properties of those systems that have not been studied. Having devised a model, the examples studied should be those which test the reliability of applicable models in an attempt to improve these models and to clearly define the limits of applicability of the models under extreme conditions by going to extreme constraints of temperature, pressure, and/or compositions to press each model to the limit to ascertain its defects and its reliability. This may well involve bypassing some substances which could be relatively easily studied in favor of more seemingly unlikely or difficult-even rare, exotic, or expensive-materials in order to develop relevant correlation schemes that would encompass practical materials.

Clearly this approach has much to recommend it in the inorganic-including mineralogical and petrological-aspects of thermodynamics; it is essentially and inherently indispensible in providing technologically-and even scientifically-useful thermophysical and thermochemical input on the tremendous diversity of molecular crystalline solids and fluids [7].

In our laboratory we are concerned mainly with cryogenic calorimetry, but in contrast to some current work in cryophysics, the prime motivation in our studies has been essentially that of the chemical thermodynamicist. This obligates us to follow a strict regimen making mandatory such matters as high purity and adequate characterization of samples, high precision and accuracy in measurement, work over an extensive range of temperatures, and careful, precise, truly-definitive work. Although the selection of a particular system for study is often based upon a structural or transitional (i.e., essentially a non-thermodynamic) objective, an important by-product of each investigation has been the provision of chemical thermodynamic data for science and technology.

\section{Correlation, tabulation and critical evaluation}

But data unknown to the designer or of unknown reliability are of little utility to technological development. Since the ambitious undertaking of the 1920's - the International Critical Tables [8] (often described as the "Intentionally Cryptic Tables") thermodynamic tables have progressed (in U.S.A.) through Bichowsky and Rossini's tabulation [9], NBS' "Circular 500" [10], and now through NBS' Standard Reference Data Program's "Series 270-X" [11] (albeit sans precision indices and sans references) now complete and soon to appear in a hard bound edition (sanitized to bars and joules) for the inorganic substances. (Our Soviet counterparts have done more 
[12-14].) The JANAF tables [15] provide temperature-dependent values for selected compounds. On the organic side, Parks and Huffman's pioneering (1932) treatise "The Free Energy of Chemical Substances" [16] was not superceded by Stull, Westrum and Sinke [17] until 1969.

But these - and other-printed tables have not managed to keep updated and only with the help of the zeroth order critical table-the "Bulletin of Chemical Thermodynamics" [18] now edited by Robert Freeman and its excellent flagging and tagging of data (both published and unpublished) - can a chemical thermodynamicist be kept abreast of progress. But only in the data-base on-line program is there hope for continual updating, integration of thermodynamic data, and the ready utilization of these data. Recognition of the urgent need for critically evaluated data is the prerequisite for appreciation of the role of CODATA.

\section{Help from CODATA}

Apart from the usual industrial, academic, and governmental facilities there exists another source of interdisciplinary data leadership in the scientific committee of the International Council of Scientific Unions (ICSU) known as CODATA-The Committee on Data for Science and Technology. I believe so strongly in the importance of this operation to science in general and to thermodynamics in particular that I have crossed the Atlantic Ocean about 200 times in the past ten years to further its endeavors. My term of office (as Secretary General) will end next month and I will then go back to full-time research and teaching.

Now in its 16 th year, it seeks to meet its statutory commitments by:

- improving the quality, reliability, and accessibility of data for science and technology

- encouraging ... necessary compilations and relevant experimental studies

- encouraging the application of new methods in data handling, storage, and retrieval ... evaluation and dissemination

- stimulating wider distribution of compilations of high quality ... maintaining directories of data compilations ... and encouraging adequate indexing of compilations, etc., etc.

Although CODATA's mandate is as broad as science itself, chemical thermodynamics-for "historical" and "accidental" reasons which need not be explored here-has, in fact, been blessed by an intensity of CODATA endeavor on its behalf not lavished on any other discipline. Let me enumerate some of these beneficial aspects performed by its task groups-the scientific "workhorses" in CODATA. 


\section{CODATA task groups}

Fundamental constants. Physical constants are central to most scientific disciplines; the forum for the review and dissemination of improved values for these constants has been provided by CODATA's Task Group on Fundamental Constants. Among the values being examined for improvement in the 1982 set is the gas constant, $R$, a magnitude of obvious interest to thermodynamicists [19].

Key values for thermodynamics. This former Task Group [20] has for the present virtually completed its mission, that of preparing a new $298.15 \mathrm{~K}$ set of definite standard enthalpies of formation and entropies for chemical species crucial to any tabulation of thermochemical and thermophysical values for calculation of equilibrium constants. The April 1978 publication of their latest report [20] covered 125 species; their final report-to be available in hard-bound form in 1983-should cover nearly 200 species [21].

Internationalization and systematization of thermodynamic tables. This Task Group [22] is charged with the development of a world-wide system for producing thermodynamic tables in an efficient, economical manner so that resulting tables will be selfconsistent no matter where they originate. That is to say "all the tables may be put on the same shelf" - whether produced by groups with interest in special areas or by major primary data centers. The group has determined that the risks of error imposed by ignoring thermodynamic self-consistency are cumulative and unacceptable. Such compatability implies interdependence of large blocks of numbers in the tables and has involved the Task Group in detailed concern with recently developed computer methods for treating large, interdependent data sets [22].

Their complex task involves systematic analysis of the methodology of obtaining such tables, delineating the requirements imposed by special classes of substances (e.g., aqueous solutions, alloys, and other multicomponent condensed-phase systems), as well as developing the documentation and reference files needed for updating. It is, of course, not restricted to printed tables but will be applicable to thermodynamic data banks as well. The Task Group will provide sample tables [23] in the near future.

Panel on data for industrial needs. This Panel is to identify broadly the data needs for industry, to seek ways of improving communication between industry and CODATA, and to examine current practices and data handling within industry, and is committed to the study of topics of industrial orientation - as distinct from scientific or academic interest-and particularly those where particular benefit is to be derived from international cooperation. It will host a workshop on the feasibility and the desirability of developing an on-line data base for the engineering properties of commercially available materials, metal, ceramics, and polymeric substances in November 1982. Other projects under study included possible supplementation to the "CODATA Directory of Sources of Data for Science and Technology" [24] reorganized by engineering disciplines, reliable characterization of adsorptive capacity of adsorbents in selective environments, toxicology of industrial materials, etc. 
Data for the chemical industry. This aggressive and active Task Group recognizes that the existing critically-evaluated technically-important physical-property data (including those of thermodynamics) are inadequate to meet the needs of the chemical industry and proposes to respond (in part) by [25]:

- guiding the expansion of existing and anticipated physical property data bases through the development of methodology for the critical evaluation of physicalproperty correlations for industrially important classes of compounds

- identifying the "key" compounds for these classes whose properties should be determined experimentally, so that the corresponding properties of all other members of that class may be abtained by estimation procedures

- developing methodology for the critical evaluation of mixture rules for technically important physical properties for likely mixtures of different classes of chemical compounds.

The Task Group has already published its guide for the presentation of physicalproperty correlations and estimation procedures [26]. Their recommendations for the selection of "key" compounds-especially suitable for the study of thermodynamicproperties-appear elsewhere [27].

\section{Other CODATA endeavors}

- Directory chapter on Chemical Thermodynamics by Robert Freeman, Chapter Editor [28],

- Publication of Calorimetric Measurements on Cellular Systems (Recommendations for Measurements and Presentation of Results) [29],

- Other adjuvant endeavors.

\section{In conclusion}

The important role played by data on thermodynamic properties in science and industry is indisputable. Neither in science nor in industry is it possible to determine beforehand in detail, just how, and to what extent a particular program will bear fruit. In science, the consequences are often unexpected. In industry, the decision regarding cost-effectiveness is likely to be very short-sighted because the real contribution is in the avoidance of disasters and the creation of conditions for efficient designs.

The advent of modern computers has led to the creation of data banks whose appetites for reliable information on thermophysical properties are insatiable. Simultaneously, the same computers make it possible to handle vast numbers of experimental data points and to extract from them, by the use of scientific principles, internally consistent and vastly expanded collections of useful and readily available data. 
Our role is clearly at the front end of the chain:

$$
\begin{aligned}
& \text { measurement } \rightarrow \text { critical evaluation } \rightarrow \text { validation } \rightarrow \text { data banking } \rightarrow \\
& \text { optimized designing } \rightarrow \text { SUCCESS. }
\end{aligned}
$$

\section{References}

1 M. L. McGlashan, Chemical Thermodynamics, Academic Press, London, p. 111, 1979.

2 D. R. Lide, Science, 212 (1981) 1343.

3 National Needs for Critically Evaluated Physical and Chemical Data (CODAN Report), National Academy of Sciences, Washington, D. C., 1978. But see also High Temperature Science: Future Needs and Anticipated Developments, National Academy of Sciences, Washington, D, C., 1979; and The Technological Importance of Accurate Thermophysical Property Information. J. V. Sengers and M. Klein, eds. NBS Special Publication No. 590. Washington, D. C., 1980.

4 Lord Rayleigh, Argon, in the Royal Institution Library of Science, Vol. 4, p. 8, L. Bragg and G. Porter, eds., Appl. Sci. Publishers, London, 1970.

5 Reference 3, CODAN Report, Appendix B.

6 A. A. Bondi, The Role of High-precision Property Data of Pure Compounds in Industrial Technology, CODATA Newsletter No. 14 (June, 1975) 6.

7 L. Brewer, in Thermodynamics and National Energy Problems, p. 8. Edited by L. Brewer, F. D. Rossini and E. F. Westrum, Jr., National Acad. of Sciences, Washington, 1974.

8 E. W. Washburn, Editor-in-Chief, International Critical Tables, Vol. V, McGrawHill, N. Y., 1929.

9 F. R. Bichowsky and F. D. Rossini, The Thermochemistry of the Chemical Substances, Reinhold, N. Y., 1936.

10 F. D. Rossini, D. D. Wagman, W. H. Evans, S. Levine and I. Jaffe, Selected Values of Chemical Thermodynamic Properties, Circular of National Bureau of Standards 500, U. S. Government Printing Office, Washington, D, C., 1952.
11 D. D. Wagman, W. H. Evans, V. B. Parker, R. H. Schumm and R. L. Nuttall, Selected Values of Chemical Thermodynamic Properties, NBS Technical Note 270-X $(X=$ Nos. $1-8)$. U. S. Government Printing Office, Washington, D. C., 1965-1981.

12 V. P. Glushko et al., Thermochemical Constants of Substances, Parts 1-8, Academy of Sciences, USSR, 1965-1978.

13 V. P. Glushko et al., Thermodynamic Properties of Pure Substances, Izd. Nauka, Moscow, 1978.

14 V. P. Glushko et al., Thermodynamic Properties of Individual Substances, Vol. I, parts 1 and 2 (1978); Vol. II, parts 1 and 2 (1979); Vol. III, parts 1 and 2 (1981); Vol. IV, parts 1 and 2 (in press), Izd. Nauka, Moscow.

15 D. R. Stull and H. Prophet, JANAF Thermochemical Tables, Second Ed., U. S. Government Printing Office, Washington, D. C., 1971. Periodically supplemented.

16 G. S. Parks and H. M. Huffman, The Free Energies of Some Organic Compounds, Chemical Catalog Co., New York, 1932.

17 D. R. Stull, E. F. Westrum, Jr. and G. C. Sinke, The Chemical Thermodynamics of Organic Compounds, J. Wiley, New York, 1969.

18 R. D. Freeman, ed., Bulletin of Chemical Thermodynamics, Thermochemistry, Inc., Oklahoma State University, 1980.

19 Recommended Consistent Values of the Fundamental Physical Constants (Report of the CODATA Task Group on Fundamental Constants), CODATA Bulletin No. 11, Pergamon Press, N. Y., 1973.

20 Tentative Set of Key Values for Thermodynamics-Part I (Report of the CODATA Task Group on Key Values for Thermodynamics), CODATA Bulletin No. 2, Pergamon Press, N. Y., 1970. 
21 J. D. Cox and D. D. Wagman, eds., Key Values for Chemical Thermodynamics (in press).

22 A Systematic Approach to the Preparation of Thermodynamic Tables (Report of the CODATA Task Group on Internationalization and Systematization of Thermodynamic Tables), CODATA Bulletin No. 47 , Pergamon Press, N. Y., 1982.

23 Format Sample Thermodynamic Tables, submitted by the Task Group on the Internationalization and Standardization of Thermodynamic Data Tables, Report to the CODATA General Assembly, Warsaw (Oct. 1982).

24 For example, CODATA Directory of Data Sources for Science and Technology, Ch. 6: Chemical Kinetics, Pergamon Press, N. Y., 1981.

25 International Council of Scientific Unions, Committee on Data for Science and Tech- nology; Mission, Activities and Goals, CODATA, Paris, 1982.

26 Guide for the Presentation in the Primary Literature of Physical Property Correlations and Estimation Procedures (Report of the CODATA Task Group on Data for the Chemical Industryl, CODATA Bulletin No. 30, Pergamon Press, N. Y., 1978.

27 B. Dreyfus, ed., Report of the First Meeting of CODATA Task Group on Data for the Chemical Industry, CODATA Newsletter No. 17, 1977.

28 CODATA Directory of Data Sources for Science and Technology, Chapter 9. Chemical Thermodynamics, Pergamon Press, N. Y. (in press).

29 Calorimetric Measurements on Cellular Systems (Recommendations for Measurements and Presentation of Results), CODATA Bulletin No. 44, Pergamon Press, N. Y., 1981.

Zusammenfassung - Im allgemeinen kommt - von wenigen Ausnahmen abgesehen - von den Bezugsdaten nur denjenigen Grundwerten eine wirkliche ökonomische Bedeutung zu, aus denen die Veränderungen der Standardenthalpien der Reaktionen und die Gibbs'schen Bildungsenergien der an der Reaktion beteiligten Stoffe berechnet werden können. Die energetischen Erfordernisse der chemischen Verfahren müssen auf exakten Werten beruhen, ebenso wie die zur Berechnung von Gleichgewichtskonstanten benötigten Gibbs-Energien. Die Genauigkeit der individuellen Werte steht dabei weniger im Vordergrund als Vielmehr die Zuverlässigkeit und leichte Zugänglichkeit der Tabellen. Der Autor geht auf die Bestrebungen der CODATA (Committee on Data for Science and Technology) und derjenigen wissenschaftlichen Gruppen ein, die sich mit der Internationalisierung und Systematisierung der für die chemische Industrie zusammengestellten thermodynamischen Tabellen sowie mit grundlegenden Konstanten und thermodynamischen Werten befassen.

Резюме - За исключением некоторых случаев, основные значения, из которых $\Delta H_{\nu}^{0}$ и $\Delta G 0$ длғ химических реакций, являются только пунктами упоминаемых данных по огношению реального экономического воздействия. Энергетические требования химической обработки требүют точных значений, точно также требуются точные значения энергий Губбса для определения констант равновесия. Даже здесь этот вклад может находится В меньшей степени в собственном значении этой точности, чем в подразумеваемой надежности и пригодности таблиц. СОDАТА приводит попытки и научные группы задач, касаюциеся основных констант, ключевых значений для термодинамики, интернационализации и систематизации термодинамических таблиц в помощь химической промышленности. 